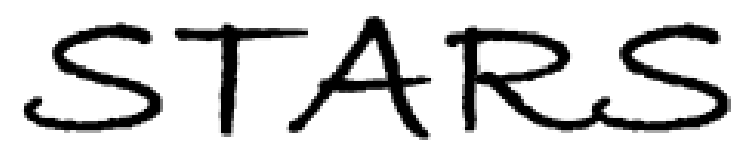

University of Central Florida

STARS

$1-1-2007$

\title{
Surface elastic properties of porous nanosilica coatings by scanning force microscopy
}

\author{
A. Vincent \\ University of Central Florida \\ S. Babu \\ University of Central Florida \\ S. Seal \\ University of Central Florida
}

Find similar works at: https://stars.library.ucf.edu/facultybib2000

University of Central Florida Libraries http://library.ucf.edu

This Article is brought to you for free and open access by the Faculty Bibliography at STARS. It has been accepted for inclusion in Faculty Bibliography 2000s by an authorized administrator of STARS. For more information, please contactSTARS@ucf.edu.

\section{Recommended Citation}

Vincent, A.; Babu, S.; and Seal, S., "Surface elastic properties of porous nanosilica coatings by scanning force microscopy" (2007). Faculty Bibliography 2000s. 7754.

https://stars.library.ucf.edu/facultybib2000/7754

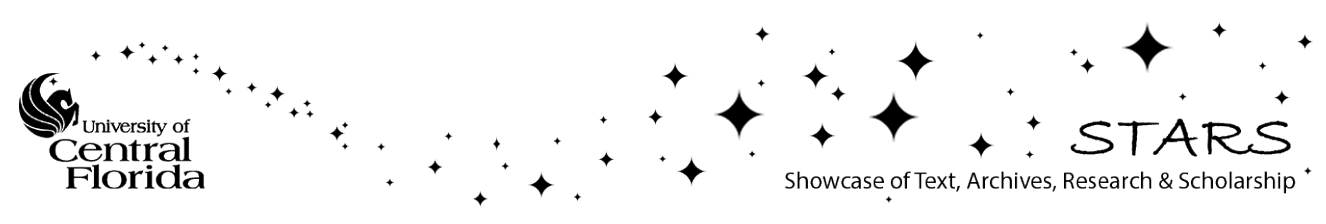




\section{Surface elastic properties of porous nanosilica coatings by scanning force microscopy}

Cite as: Appl. Phys. Lett. 91, 161901 (2007); https://doi.org/10.1063/1.2799249

Submitted: 01 September 2007 . Accepted: 25 September 2007 . Published Online: 15 October 2007

A. Vincent, S. Babu, and S. Seal

ARTICLES YOU MAY BE INTERESTED IN

Elastic modulus of polystyrene film from near surface to bulk measured by nanoindentation using atomic force microscopy

Applied Physics Letters 89, 031925 (2006); https://doi.org/10.1063/1.2234648

Calibration of atomic-force microscope tips

Review of Scientific Instruments 64, 1868 (1993); https://doi.org/10.1063/1.1143970

Calibration of rectangular atomic force microscope cantilevers

Review of Scientific Instruments 70, 3967 (1999); https://doi.org/10.1063/1.1150021

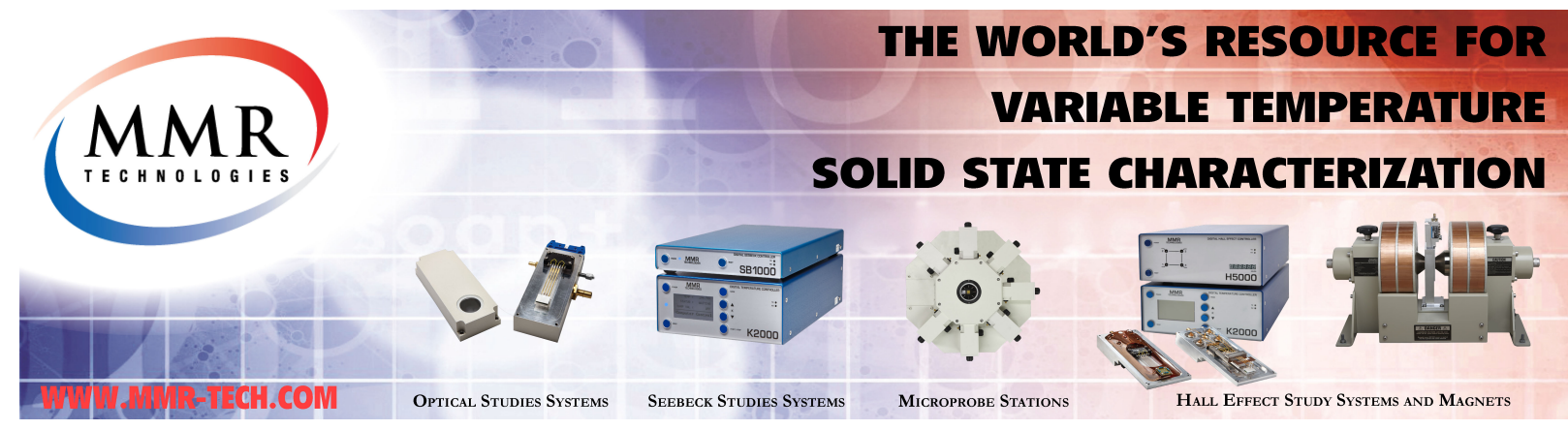




\title{
Surface elastic properties of porous nanosilica coatings by scanning force microscopy
}

\author{
A. Vincent, S. Babu, and S. Seal ${ }^{a)}$ \\ Advanced Material Processing and Analysis Center (AMPAC), Nanoscience Technology Center, \\ Mechanical, Materials, and Aerospace Engineering Department, University of Central Florida, \\ Orlando, Florida 32816, USA
}

(Received 1 September 2007; accepted 25 September 2007; published online 15 October 2007)

\begin{abstract}
Surface elastic properties of sol-gel derived porous nanosilica optical coatings were determined using scanning force microscopy. Silica nanocoatings prepared under acid and base catalyzed sol-gel process exhibited varying surface morphology, particle size and porosity. Force-distance spectroscopy measurements were conducted on these coatings using scanning force microscopy, and their elastic moduli were obtained by applying Hertz model. The elastic modulus of the coatings varied from 2.4 to $13.4 \mathrm{GPa}$ depending on the nature and concentration of the catalyst used. (C) 2007 American Institute of Physics. [DOI: 10.1063/1.2799249]
\end{abstract}

Influence of porosity in mechanical properties such as elastic modulus and Poisson's ratio has been a subject of interest of many researchers as the elastic modulus decreases with an increase in porosity ${ }^{1}$ and a decrease in density. ${ }^{2}$ Earlier, we have reported porous silica coatings for antireflective coatings with $99 \%$ and above transmittance on boron silicate glass substrate. ${ }^{3}$ We found that the refractive index of these coatings can be tuned by varying the particle size and porosity. However, an increase in particle size and porosity can affect the bonding between the particles and modify the mechanical strength. ${ }^{4}$ Hence, it is necessary to understand the influence of porosity and particle size on the mechanical properties of these films.

Mechanical response of the surfaces to forces at nanoscale and nanometer penetration depth levels has been possible with scanning force microscope (SFM) ${ }^{5-14}$ where the applied load can be controlled in nano- to piconewtons by changing the tip curvature radius and cantilever stiffness. ${ }^{7}$ Herein, we report the surface elastic modulus obtained as a function of microstructure and porosity by force-distance spectroscopy on porous silica coatings prepared by acid and base catalyzed sol-gel process.

The details of silica sol-gel synthesis and coating preparation are reported elsewhere. ${ }^{3}$ Using the acid catalysis, less porous and highly dense coatings can be achieved while the use of base catalyst results in highly porous and less dense silica coatings. In our experiments, depending on the nature of the catalyst (acid or base), the samples were coded as A or B. It is to be noted that only one molar ratio of acid catalyzed silica sample was chosen tetraethyl orthosilicate (TEOS) to $\mathrm{HNO}_{3}$ molar ratio of 1:0.025), while two different molar ratios of base catalyzed silica samples (TEOS to $\mathrm{NH}_{4} \mathrm{OH}$ molar ratio of 1:1 and 1:3) were used for the experiment, as the variation in molar ratio of acid catalyst did not result in marked variation on surface morphology and mechanical properties among other acid catalyzed samples. The coatings were deposited on boron silicate glass by dip coating.

Figure 1 shows the force-distance $(F-d)$ curves acquired on a relatively smooth area [selected based on atomic force microscopy (AFM) image] of the individual coating samples

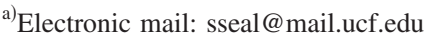

as well as on the glass substrate at a load of $2.0 \mu \mathrm{N}$ using scanning force microscopy (Solver EC, NT-MDT, Russia). Acquisition of the force curve at several points was conducted for better uniformity and repeatability. All measurements were made with a silicon cantilever having a tip size of $20 \mathrm{~nm}$ in diameter. These curves are then compared with the curve on the blank glass substrate. Since the silicon tip could not penetrate the hard glass substrate (AFM images shows no sign of indentation on glass substrate), the $z$ axis movement of the piezostage (linear solid curve, $G$ in Fig. 1) represents only cantilever deflection and no indentation while collecting force curves on the blank substrate. Considering the $F$ - $d$ curves of the coatings, there is a clear trend of decrease in slope as well as deviation in the linear nature of the curve due to tip indentation. The difference in the piezoheight between the substrate and the silica coatings provides the depth of indentation. The cantilever deflection $D$ (in nanoampere) can be converted into the applied load $F$ (in

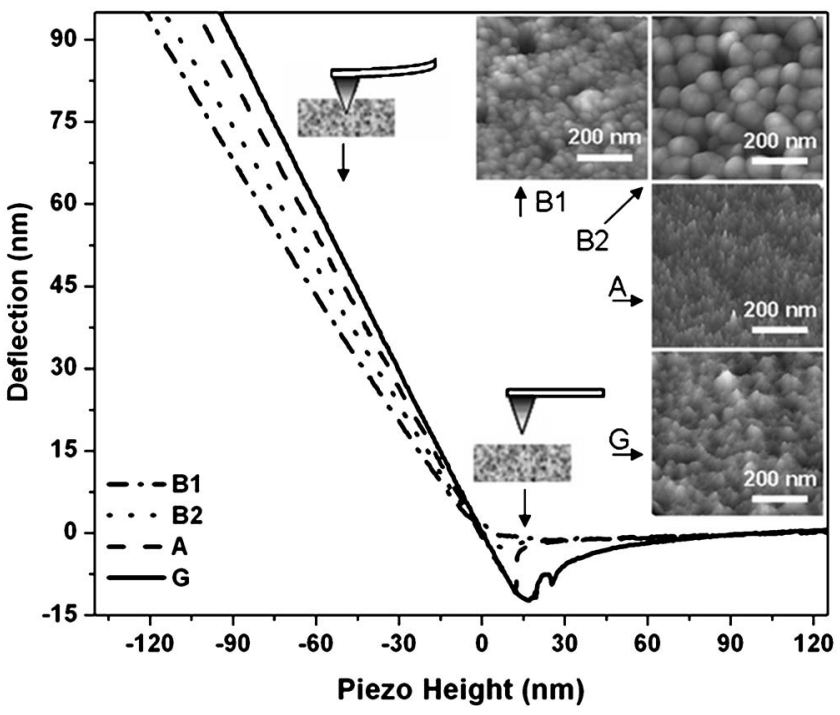

FIG. 1. Force-distance curves obtained from base catalyzed silica coatings (B1 and B2), acid catalyzed silica coating (A), and a bare glass substrate (G). Inset shows the corresponding AFM images of the samples. Particle size increases with an increase in the basic nature of the catalyst. The mean particle size was found to be 5, 30, and $100 \mathrm{~nm}$ for A, B1, and B2, respectively. 


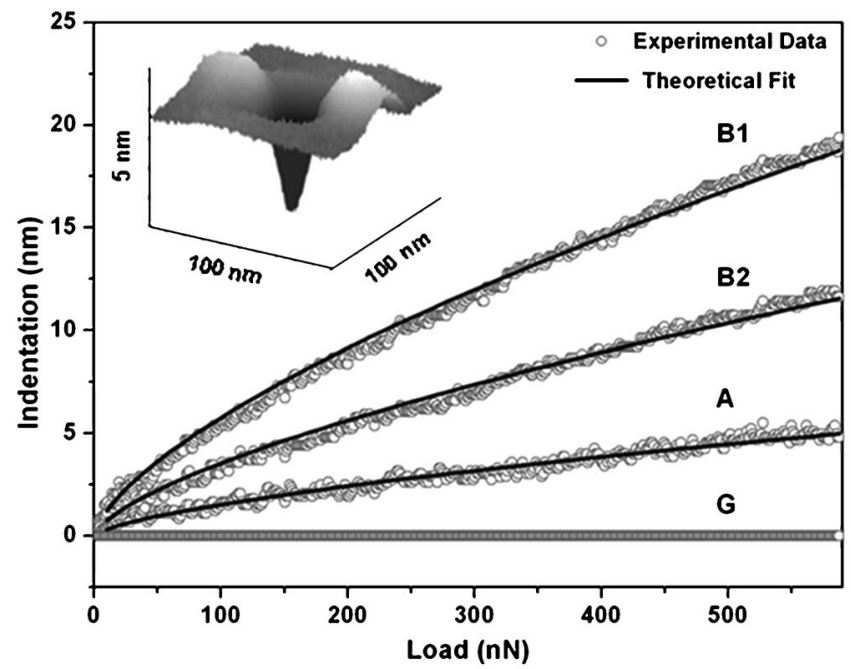

FIG. 2. Load-Indentation profile obtained from base catalyzed and acid catalyzed silica coatings. The power law fitting coefficient for each of the curves is listed in Table I. Inset shows the three dimensional surface profile of an indent obtained on an acid catalyzed coating.

nanonewton) using the relation $F=k D / S$, where $k$ is the spring constant (in $\mathrm{nN} / \mathrm{nm}$ ) determined using the method of Sader et al. $^{15}$ and $S$ is the sensitivity (in $\mathrm{nA} / \mathrm{nm}$ ) obtained from the slope of the $F$ - $d$ curve on the glass substrate. Base catalyzed silica coatings showed lower resistance to indentation as indicated by the decrease in the slope of the $F-d$ curves, and hence exhibits lower mechanical strength (higher depth of indentation) in comparison to the acid catalyzed silica coating. It is now possible to calculate the tip indentation $\Delta z$ into the soft sample as the difference in the respective piezoheight and $z$ positions relative to the blank glass reference. The elastic deformation has been defined through Hertz equation ${ }^{9-14}$ for a parabolic indenter (parabolic indenter is the most reasonable approximation for an SFM tip), as $F=(4 / 3) E_{r} R^{1 / 2} \delta^{3 / 2}$, where $E_{r}$ is the reduced elastic modulus (also called as effective elasticity), $R$ is the radius of the indenter, and $\delta$ is the indentation depth. The elastic modulus of the sample $E_{s}$ can be obtained from the sample tip interaction and is given by, $1 / E_{r}=\left(1-\nu_{t}^{2}\right) / E_{t}+\left(1-\nu_{s}^{2}\right) / E_{s}$, where $\nu$ is the Poisson's ratio, and $E_{t}$ and $E_{s}$ is the elastic modulus of the tip and sample, respectively. The elastic modulus and the Poison ratio of silicon tip were taken from the literature $\left(E_{t}=130 \mathrm{GPa}\right.$ and $\left.\nu_{t}=0.27\right) .{ }^{16}$ Poisson's ratio of 0.22 was assumed for silica film and it was reported to be not affected by the variation in film density. ${ }^{17}$ Hertzian model can be applied only when $E_{t}>E_{s}$. ${ }^{11}$ The model is valid only for elastic deformation and assumes no significant adhesion between the tip and the sample. ${ }^{18}$ It is important to avoid any contribution from inelastic deformation and tip-sample adhesion during the analysis of the load displacement curve. The adhesion between contacting bodies becomes more significant at nanoscale. ${ }^{19}$ We have observed adhesion between the tip and silica coatings during unloading. Also in the case of base catalyzed silica films, cracking and pileup of material were observed during indentation due to plastic deformation. Hence, only the initial elastic deformation region of the loading curve was analyzed for elastic modulus determination.

Nanoindentation curves obtained on base and acid catalyzed silica coatings are shown in Fig. 2. The effective elastic modulus of the coatings can be obtained from the indentation curve through power law regression analysis using the following equation, $\delta=a F^{b}$, where $\delta$ is the indentation depth, and $a$ and $b$ are the fitting parameters. The value of power $b$ is fixed as $2 / 3$ by applying the Hertz model, and the value of coefficient $a$ can be obtained by power law regression fitting (values of coefficient $a$ are listed in Table I). From the parabolic tip model, the reduced elastic modulus $E_{r}$ can be calculated as $E_{r}=3 /\left(4 a^{3 / 2} R^{1 / 2}\right)$, where $R$ is the tip radius.

The elastic modulus calculated for acid and base catalyzed coatings are listed in Table I. Among all the coatings, acid catalyzed silica coatings showed the highest elastic modulus (13.4 GPa) and is close to the earlier reported values for sol-gel silica coating. ${ }^{20,21}$ This higher value of elastic modulus compared to base catalyzed silica is due to the low porous nature $(5 \%)$ and higher density $(2.18 \mathrm{~g} / \mathrm{cc})$ of the coatings. Unlike polycrystalline materials whose mechanical properties largely depends on the nature of grain boundaries, mechanical properties of glassy materials such as silica depend more on composition and structure of the bonding network. $^{22}$ Elastic modulus value calculated for base catalyzed silica coating $\mathrm{B} 1$ is $1.63 \mathrm{GPa}$, and is close to the reported values for porous silica. ${ }^{22}$ The lower value of elastic modulus is due to the presence of large number of pores in the film as the B1 silica film is approximately $49 \%$ porous in nature and the density is very low $(1.17 \mathrm{~g} / \mathrm{cc})$. Due to their high porous nature, porous silica coatings often exhibit very low density ${ }^{23}$ and their elastic modulus can be even $10^{2}-10^{4}$ smaller than that of silica glass. ${ }^{24}$ Coatings obtained from porous silica sol-gel contain roughness in the form of asperities. Presence of these asperities will increase the surface area over which the tip and the sample make the effective contact. This leads to a reduced contact pressure for a given load and results in a lower value of elastic modulus. ${ }^{10}$ In order to determine the significance of surface roughness on elastic modulus determination, a nondimensional parameter $\alpha$ has to be considered. $\alpha=\sigma_{s} R / a_{0}^{2}=\sigma_{s}\left(16 R E_{r}^{2} / 9 F^{2}\right)^{1 / 3}$, where $\sigma_{s}$ is the rms roughness obtained experimentally and $a_{0}$ is the contact radius for smooth surfaces under the load $F$. The Hertz theory for smooth surfaces is valid only if the parameter $\alpha$ is less than $0.05{ }^{25}$ The value of $\alpha$ calculated for acid catalyzed silica coating with a low surface roughness of $0.3 \mathrm{~nm}$ is less than 0.05 which is within the error limit.

TABLE I. Structural and elastic properties of acid and base catalyzed silica coatings.

\begin{tabular}{ccccccccc}
\hline \hline & $\begin{array}{c}\text { Film } \\
\text { Thin } \\
\text { thilm } \\
(\mathrm{nm})^{\mathrm{a}}\end{array}$ & $\begin{array}{c}\text { Particle } \\
\text { diameter } \\
(\mathrm{nm})^{\mathrm{a}}\end{array}$ & $\begin{array}{c}\text { Roughness } \\
(\mathrm{nm})^{\mathrm{a}}\end{array}$ & $\begin{array}{c}\text { Pore } \\
\text { radius } \\
(\mathrm{nm})^{\mathrm{a}}\end{array}$ & $\begin{array}{c}\text { Porosity } \\
(\%)^{\mathrm{a}}\end{array}$ & $\begin{array}{c}\text { Density } \\
(\mathrm{g} / \mathrm{cc})^{\mathrm{a}}\end{array}$ & $\begin{array}{c}\text { Power law } \\
\text { coefficient } a\end{array}$ & $\begin{array}{c}\text { Elastic } \\
\text { modulus } \\
(\mathrm{GPa})\end{array}$ \\
\hline A & $635 \pm 2$ & $5.9 \pm 1.1$ & 0.3 & 1.7 & 5.0 & 2.18 & 0.00007 & 13.40 \\
B2 & $105 \pm 2$ & $99.5 \pm 20.7$ & 3.0 & 14 & 36.1 & 1.47 & 0.00017 & 5.02 \\
B1 & $110 \pm 2$ & $33.5 \pm 8.8$ & 4.5 & 4.7 & 49.1 & 1.17 & 0.00027 & 2.38 \\
\hline \hline
\end{tabular}

${ }^{\mathrm{a}}$ Ref. 3. 


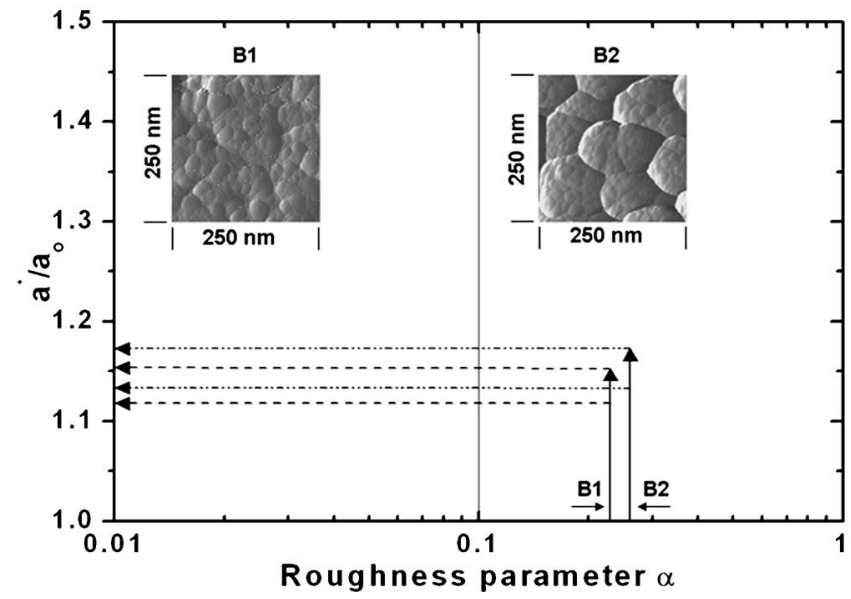

FIG. 3. Influence of surface roughness on the effective contact radius $a^{*}$ compared with the Hertz radius $a_{0}$ for two values of $\mu$ that encompass a wide range of practical rough surfaces (Ref. 26). For coating B1, $\alpha=0.23$ and $4<\mu<17$, and $a^{*} / a_{0}$ is between 1.12 and 1.15 , and for coating B2, $\alpha=0.26$ and $4<\mu<17$, and $a^{*} / a_{0}$ is between 1.13 and 1.17. Inset shows the amplitude contrast AFM image of base catalyzed silica coatings

Hence, no roughness correction is required for acid catalyzed silica coating. However, the value of $\alpha$ calculated for base catalyzed silica coating B1 with a surface roughness of $4.5 \mathrm{~nm}$ is $0.23(>0.05)$, and the value of value of $\alpha$ calculated for base catalyzed silica coating B2 with a local cluster surface roughness of $3 \mathrm{~nm}$ is $0.26(>0.05)$. A second nondimensional parameter $\mu$, defined by Greenwood and Tripp ${ }^{26}$ is given by $\mu=(8 / 3) \eta_{s} \sigma_{s}\left(2 R / \kappa_{s}\right)^{1 / 2}$, where $\mu_{s}$ is the asperity density and $\kappa_{s}$ is the mean curvature of the summits of asperities. Greenwood and Tripp obtained two values of $\mu$, which is bracketed by a wide range of practical rough surfaces. Using these two parameters, $\alpha$ and $\mu$, the correction required for elastic modulus is determined. The ratio of effective contact radius (experimental), $a^{*}$ to the Hertz radius (theoretical), $a_{0}$ are influenced by the surface roughness, as shown in Fig. 3. Since $E$ is proportional to $1 / a^{3}$, the elastic modulus value after the roughness correction for base catalyzed silica coating B1 is approximately $2.38 \mathrm{GPa}$. In the case of base catalyzed silica coating B2, the coating was mainly formed by individual silica agglomerates (clusters) of size closer to $100 \mathrm{~nm}$ (AFM image of B2 in Fig. 1) and contained larger size pores. However, B2 silica coatings were less porous (approximately 36\%) than that of B1 silica coatings. Due to the larger size of silica agglomerates compared to SFM tip diameter, the indentation experiments conducted on these agglomerates particles only represents the mechanical properties of the skeletal silica agglomerates and not that of the porous silica coating. The elastic modulus of individual silica agglomerates obtained after the roughness correction is approximately $5.02 \mathrm{GPa}$. The amplitude contrast AFM images of B2 silica coatings (inset of Fig. 3) showed that these silica clusters are agglomerates of smaller size (diameter of approximately $20 \mathrm{~nm}$ ) particles with a local cluster surface roughness of $3.0 \mathrm{~nm}$. The bonding strength between these individual particles determines the mechanical properties of these bigger agglomerates. The reason for lower value of elastic modulus of these silica agglomerates is mainly due to the weaker bonding between the individual amorphous particles.

Porous silica optical coatings obtained by acid and base catalyzed synthesis showed variation in elastic modulus depending on the microstructure and nature of the coatings. From SFM indentation curves, using the Hertz model, we have obtained the elastic modulus of thin film silica optical coatings. Acid catalyzed silica coatings were denser in nature and exhibited higher elastic modulus than base catalyzed silica samples. Among the two base catalyzed silica coatings, the particle size, microstructure and porosity greatly influenced the individual elastic modulus values.

The authors thank Lockheed Martin and Florida High Tech Corridor for the funding.

${ }^{1}$ B. B. Avar, N. Hudyma, and M. Karakouzian, Int. J. Rock Mech. Min. Sci. 40, 919 (2003).

${ }^{2}$ H. Fan, C. Hartshorn, T. Buchheit, D. Tallant, R. Assink, R. Simpson, D. J. Kissel, D. J. Lacks, S. Torquato, and C. J. Brinker, Nat. Mater. 6, 418 (2007).

${ }^{3}$ A. Vincent, S. Babu, E. Brinley, A. Karakoti, S. Deshpande, and S. Seal, J. Phys. Chem. C. 111, 8291 (2007).

${ }^{4}$ Y. Chen, K. Balani, and A. Agarwal, Appl. Phys. Lett. 91, 031903 (2007).

${ }^{5}$ G. M. Pharr and W. C. Oliver, MRS Bull. 17, 28 (1992).

${ }^{6}$ A. B. Nancy and J. C. Richard, J. Vac. Sci. Technol. A 7, 2906 (1989).

${ }^{7}$ K. Miyake, N. Satomi, and S. Sasaki, Appl. Phys. Lett. 89, 031925 (2006).

${ }^{8}$ M. B. Salmeron, MRS Bull. 18, 20 (1993).

${ }^{9}$ A. J. Heim, W. G. Matthews, and T. J. Koob, Appl. Phys. Lett. 89, 181902 (2006).

${ }^{10}$ E. P. S. Tan and C. T. Lim, Appl. Phys. Lett. 87, 123106 (2005).

${ }^{11}$ C. Munuera, T. R. Matzelle, N. Kruse, M. F. Lopez, A. Gutierrez, J. A. Jimenez, and C. Ocal, Acta Biomat. 3, 113 (2007).

${ }^{12} \mathrm{M}$. Salerno and I. Bykov, Microscopy and Analysis 20, S5 (2006).

${ }^{13}$ S. Garcia-Manyes, A. G. Güell, P. Gorostiza, and F. Sanz, J. Chem. Phys. 123, 114711 (2005)

${ }^{14}$ A. Touhami, B. Nysten, and Y. F. Dufrene, Langmuir 19, 4539 (2003).

${ }^{15}$ J. E. Sader, J. W. M. Chon, and P. Mulvaney, Rev. Sci. Instrum. 70, 3967 (1999).

${ }^{16}$ W. A. Brantley, J. Appl. Phys. 44, 534 (1973).

${ }^{17}$ J. Gross, G. Reichenauer, and J. Fricke, J. Phys. D 21, 1447 (1988).

${ }^{18}$ M. Perkins, S. J. Ebbens, S. Hayes, C. J. Roberts, C. E. Madden, S. Y. Luk, and N. Patel, Int. J. Pharm. 332, 168 (2007).

${ }^{19}$ R. Gissi and P. Decuzzi, J. Appl. Phys. 98, 014310 (2005).

${ }^{20}$ C. M. Chan, G. Z. Cao, H. Fong, M. Sarikaya, T. Robinson, and L. Nelson, Mater. Res. 15, 148 (2000).

${ }^{21}$ S. Yu, T. K. S. Wong, X. Hu, and M. S. Yong, J. Sol-Gel Sci. Technol. 35, 69 (2005).

${ }^{22}$ S. Takada, N. Hata, Y. Seino, K. Yamada, Y. Oku, and T. Kikkawa, Jpn. J. Appl. Phys., Part 1 43, 2453 (2004).

${ }^{23}$ M. Moner-Girona, A. Roig, E. Molins, E. Martinez, and J. Esteve, Appl. Phys. Lett. 75, 653 (1999).

${ }^{24}$ M. Gronauer and J. Fricke, Acustica 59, 177 (1986).

${ }^{25}$ K. L. Johnson, Contact Mechanics (Cambridge University Press, Cambridge, 1985), pp. 397-423.

${ }^{26}$ J. A. Greenwood and J. H. Tripp, J. Appl. Mech. 34, 153 (1967). 